\title{
QUEEN'S
UNIVERSITY
BELFAST
}

\section{Paraoxonase activity and coronary heart disease risk in healthy middle-aged males: the prime study}

Troughton, J. A., Woodside, J., Yarnell, J., Arveiler, D., Amouyel, P., Ferrieres, J., Ducimetiere, P., Patterson, C., Luc, G., Evans, A., \& Kee, F. (2008). Paraoxonase activity and coronary heart disease risk in healthy middleaged males: the prime study. Atherosclerosis, 197(2), 556-563.

https://doi.org/10.1016/j.atherosclerosis.2007.08.019

Published in:

Atherosclerosis

Queen's University Belfast - Research Portal:

Link to publication record in Queen's University Belfast Research Portal

\section{General rights}

Copyright for the publications made accessible via the Queen's University Belfast Research Portal is retained by the author(s) and / or other copyright owners and it is a condition of accessing these publications that users recognise and abide by the legal requirements associated with these rights.

Take down policy

The Research Portal is Queen's institutional repository that provides access to Queen's research output. Every effort has been made to ensure that content in the Research Portal does not infringe any person's rights, or applicable UK laws. If you discover content in the Research Portal that you believe breaches copyright or violates any law, please contact openaccess@qub.ac.uk. 


\title{
Paraoxonase activity and coronary heart disease risk in healthy middle-aged males: The PRIME study
}

\author{
J.A. Troughton ${ }^{\text {a }}$, J.V. Woodside ${ }^{\mathrm{a}, *}$, J.W.G. Yarnell ${ }^{\mathrm{a}}$, D. Arveiler ${ }^{\mathrm{b}}$, \\ P. Amouyel ${ }^{\mathrm{c}}$, J. Ferrières $^{\mathrm{d}}$, P. Ducimetière ${ }^{\mathrm{e}}$, C.C. Patterson ${ }^{\mathrm{a}}$, G. Luc ${ }^{\mathrm{f}}$, \\ on behalf of the PRIME Study Group ${ }^{1}$ \\ ${ }^{a}$ Faculty of Medicine, Queen's University Belfast, Belfast, Northern Ireland, UK \\ b Strasbourg MONICA Project, Department of Epidemiology and Public Health, Faculty of Medicine, Strasbourg, France \\ ${ }^{\mathrm{c}}$ Lille MONICA Project, INSERM U508, Pasteur Institute of Lille, Lille, France \\ d Toulouse MONICA Project, INSERM U588, Department of Epidemiology, Paul Sabatier-Toulouse Purpan University, Toulouse, France \\ e Coordinating Center, INSERM U258, Hôpital Paul Brousse, Villejuif, France \\ ${ }^{\mathrm{f}}$ The Department of Atherosclerosis, INSERM U545, Institut Pasteur de Lille, Université de Lille 2, Lille, France \\ Received 10 April 2007; received in revised form 11 August 2007; accepted 20 August 2007 \\ Available online 27 September 2007
}

\begin{abstract}
Objective: Classic coronary heart disease (CHD) risk factors fail to explain the large gradient in CHD incidence between Northern Ireland and France. The Prospective Epidemiological Study of Myocardial Infarction (PRIME) study, a multicentre prospective study of 10,593 middle-aged males, investigated novel risk factors in these populations. We tested the hypotheses that (1) higher paraoxonase activity is associated with decreased CHD risk and (2) PON55 LL genotype is associated with increased CHD risk.

Methods: Paraoxonase activity was measured in 299 men who had developed CHD at 5-year follow-up and in 576 matched controls. DNA was available from 247 cases and 433 controls for genotyping for the PON55 polymorphism.

Results: There was no significant difference in paraoxonase activity between cases and controls (geometric means 73.8 and 74.2 U/l; $p=0.81$ ). There was no significant difference in CHD risk between fifths of paraoxonase activity either before $(p=0.55)$ or after adjustment for classical risk factors $(p=0.58)$.

There was no significant association between genotype and CHD risk; relative to the LL genotype, the OR (95\% CI) for the LM and MM genotypes were $0.92(0.66-1.29)$ and $0.83(0.50-1.36)$, respectively. The frequency of the L allele in cases $(66.6 \%)$ and controls $(64.5 \%)$ did not differ significantly, $p=0.45$.

Conclusions: These findings suggest that neither paraoxonase activity nor PON55 genotype is associated with CHD risk in males in the PRIME study.
\end{abstract}

(C) 2007 Elsevier Ireland Ltd. All rights reserved.

Keywords: Paraoxonase; PON55; Coronary heart disease; Prospective; Cohort; PRIME

\section{Introduction}

CHD is responsible for $50 \%$ of all mortality in developed countries [1]. Classic risk factors such as smoking, male gen-

\footnotetext{
* Corresponding author at: Department of Medicine, Mulhouse Building, Grosvenor Road, Belfast BT12 6BJ, UK. Tel.: +44 28 90632585; fax: +44 2890235900 .

E-mail address: j.woodside@qub.ac.uk (J.V. Woodside).

1 See Appendix A.
}

der, hypertension and hyperlipidaemia do not fully explain the risk of developing CHD [2]. There is a large difference in incidence of CHD between Northern Ireland and France that is only partly explained by classical risk factors [3], indicating that novel risk factors are likely to play a role in CHD aetiology [4]. The PRIME study (Prospective Epidemiological Study of Myocardial Infarction) was set up to investigate possible reasons for the difference in CHD incidence between Northern Ireland and France. There are four 
centres: three in France (Lille in the north, Strasbourg in the east and Toulouse in the southwest) and one in Belfast, Northern Ireland.

Paraoxonase (PON) is an enzyme found bound to a subfraction of HDL containing apoA-I [5]. It has two polymorphisms within its coding region: at position 192 glutamine (Q) has low activity toward paraoxon hydrolysis whereas arginine $(\mathrm{R})$ has high activity [6,7]; and at position 55 methionine $(\mathrm{M})$ has low activity whereas leucine $(\mathrm{L})$ has high activity [8].

Paraoxonase protects both LDL and HDL from oxidation [9] but is inactivated by ox-LDL [10], decreasing its protective capability [11]. The low-activity MM genotype is more protective against LDL oxidation than the LL genotype [12].

To date, there has been only one prospective study investigating the association between paraoxonase activity and CHD risk [13]. However, a cross-sectional study has suggested that there is a difference in PON activity between healthy Northern Irish and French populations [14].

Thus, the aim of the PRIME study was first to investigate prospectively whether there was an independent association between paraoxonase activity and CHD risk in healthy middle-aged men and secondly, to determine whether there was an association between the PON55 polymorphism and CHD risk.

This is only the second study to examine prospectively the association between paraoxonase activity and CHD risk, and includes two populations known to have different levels of CHD risk [15].

\section{Methods}

Recruitment and examination methods have been described previously $[3,16]$, but will be summarised briefly. Participation was voluntary and all subjects signed a consent form.

\subsection{Population recruitment}

Between 1991 and 1993, 10,593 men aged 50-59 years were recruited from industry, various employment groups and general practice in four centres, three in France and one in Northern Ireland. The sample was recruited to match broadly the social class structure of the population.

\subsection{Personal history}

Each subject completed self-administered questionnaires on demographic, socio-economic factors and dietary habits. Additional data on tobacco and alcohol consumption, and physical activity were collected during clinic attendance, and the London School of Hygiene Cardiovascular (Rose) Questionnaire for Chest Pain on Effort and Possible Infarction [17] was also administered.

\subsection{Clinical examination}

Baseline investigations included a standard 12-lead electrocardiogram, and standardised blood pressure measurement. Anthropometric measurements included height, weight and waist and hip circumferences. Body mass index (BMI) and waist-hip ratio (WHR) were then calculated.

\subsection{Pre-existing $C H D$}

Subjects were considered to have CHD at entry if they reported at least one of the following events:

(i) myocardial infarction (MI) and/or angina pectoris diagnosed by a physician,

(ii) electrocardiographic evidence of MI,

(iii) a positive answer to the Rose questionnaire [17].

There were 9758 subjects without evidence of CHD at study entry, 7359 in France and 2399 in Northern Ireland.

\subsection{Case-control selection and follow-up}

Subjects were contacted annually by letter and asked to complete a clinical event questionnaire. Coronary events were defined as the presence of at least one of the following: non-fatal MI, death from CHD or angina pectoris [16].

Five-year follow-up has been completed. The total number of new CHD cases identified was 335. Each case was matched to two controls who were study participants of the same age ( \pm 3 years), recruited in the same centre at the same time ( \pm 2 days) as the corresponding case and were free of CHD on the date of the ischaemic event of the case. Data were available for biochemical analysis on 299 cases and 576 controls, due to a limited volume of serum sample available. DNA was available for genotyping from 247 cases and 433 controls because consent for genetic analysis was not obtained from all participants. In the event that consent for DNA analysis was obtained from a case but not from one or both of its matched controls, new controls were selected from amongst those consenting for genotype analysis. Thus, the case-control matching for the genotype analysis differed slightly from the case-control matching in the phenotype analysis.

\subsection{Laboratory measurements}

Venous blood samples were collected after a $12 \mathrm{~h}$ fast. Measurement of total and high-density lipoprotein (HDL) cholesterol, triglycerides, apolipoprotein B, glutathione peroxidase, fibrinogen, apolipoprotein A1 (apoA-1) and Lp(a) were performed during the recruitment phase on all subjects. Glucose, bilirubin, cystatin $\mathrm{C}, \mathrm{B}_{12}$, folate and homocysteine were also measured in samples which were collected during the recruitment phase but stored until the 5-year follow-up was complete, and analysed only in subjects selected for the case-control study. 
Plasma for lipid analysis was sent weekly at $4{ }^{\circ} \mathrm{C}$ to SERLIA-INSERM U325 (Pasteur Institute, Lille, France), the coordinating laboratory. Methods used to measure baseline lipid parameters, have been described previously [3].

Paraoxonase hydrolyses paraoxon to diethylphosphate and $p$-nitrophenol. Enzyme activity is expressed as $\mathrm{U} / \mathrm{l}$, which is defined as $1 \mu \mathrm{mol}$ of $p$-nitrophenol generated per minute per litre under assay conditions.

At the optimum $\mathrm{pH}$ of this assay, $\mathrm{pH} 10.5$, esterase activity by albumin contributes to paraoxonase activity [18]. However, at neutral $\mathrm{pH} 7.5-8.5$ the contribution of the albumin-associated activity is minimal, while paraoxonase activity is between approximately 10 and $50 \%$ [18]. Therefore, activity was measured at $\mathrm{pH} 8.0$.

The amount of $p$-nitrophenol produced is calculated from the increase in absorbance at $412 \mathrm{~nm}$ and $25^{\circ} \mathrm{C}$ in an automated colorimetric assay performed on a Cobas Fara analyser using the millimolar absorbance coefficient of $p$-nitrophenol, which is 17.1 at $\mathrm{pH} 8.0$ [19].

The serum sample to be tested was added to a cuvette containing $1 \mathrm{mmol} / \mathrm{l}$ paraoxon, $1 \mathrm{mmol} / 1 \mathrm{CaCl}_{2}$ and $50 \mathrm{mmol} / \mathrm{l}$ Tris-HCl buffer at $\mathrm{pH}$ 8.0. Blanks contained substrate without enzyme.

The intra-assay coefficient of variation $(\mathrm{CV})$ was $1.89 \%$ at a mean of $162.5 \mathrm{U} / 1(n=16)$, while the inter-assay $\mathrm{CV}$ using the same quality control material was $2.05 \%(n=6)$.

PON55 genotyping was performed using polymerase chain reaction on a $2 \mu \mathrm{l}$ sample of DNA in a $25 \mu \mathrm{l} \mathrm{PCR}$ mix. Each PCR mix contained $0.2 \mathrm{mmol} / \mathrm{l}$ dNTPs (Promega, Southampton, UK), $1.5 \mathrm{~mol} / 1 \mathrm{MgCl}_{2}$ (Promega), $2.5 \mu \mathrm{l}$ of Promega storage buffer 10 (i.e. $50 \mathrm{mmol} / \mathrm{l} \mathrm{KCl}, 10 \mathrm{mmol} / \mathrm{l}$ Tris- $\mathrm{HCl} \mathrm{pH} 9.0$ at $25^{\circ} \mathrm{C}$ and $0.1 \%$ Triton $^{\mathrm{TM}} \mathrm{X}-100$ ), $0.25 \mu \mathrm{mol} / 1$ of each primer (forward $5^{\prime}$ GAA GAG TGA TGT ATA GCC CCA G 3'; reverse 5' TTT AAT CCA GAG CTA ATG AAA GCC $3^{\prime}$ supplied by MWG Biotech, Milton Keynes, UK), $0.75 \mathrm{U}$ of Taq DNA polymerase (Promega) and $0.1 \mu \mathrm{g}$ DNA. A negative control containing only $25 \mu$ of PCR mix, with no DNA, was included in each amplification run to ensure that there was no DNA contamination.

The following PCR conditions were set up on an Eppendorf DNA thermocycler:

$\left.\begin{array}{ll}95^{\circ} \mathrm{C} & 4 \mathrm{~min} \\ 95^{\circ} \mathrm{C} & 1 \mathrm{~min} \\ 54.4^{\circ} \mathrm{C} & 1 \mathrm{~min} \\ 72^{\circ} \mathrm{C} & 1 \mathrm{~min}\end{array}\right\} 35$ cycles $\quad\left\{\begin{array}{l}\text { Enzyme activation } \\ \text { PNA denaturation } \\ \text { Primer annealing } \\ \text { DNA synthesis }\end{array}\right.$

$72^{\circ} \mathrm{C} \quad 10 \mathrm{~min} \quad 1$ cycle Final extension step.

The $15 \mu \mathrm{l}$ of PCR product was digested with $10 \mathrm{U}$ of the enzyme Hsp 92II (Promega) in the presence of $10 \times$ Buffer K and BSA (both Promega) for $16 \mathrm{~h}$ at $37^{\circ} \mathrm{C}$ and then resolved by electrophoresis on a $3 \%$ agarose gel stained with ethidium bromide. The $\mathrm{L}$ and $\mathrm{M}$ alleles were assigned on the basis of the presence of $170 \mathrm{bp}$ (no digestion), $126 \mathrm{bp}$ (partial diges- tion) and $44 \mathrm{bp}$ (complete digestion) fragments, respectively. Fragment size was determined using a 50 bp gene ruler (MBI Fermenture, Sunderland, England).

\subsection{Statistical analysis}

Variables with a skewed distribution (paraoxonase and triglycerides) were logarithmically transformed prior to analysis and results summarised as geometric mean and interquartile range. Pearson correlation coefficients were used to investigate the association between paraoxonase activity and other CHD risk factors separately in cases and controls. Independent samples $t$-tests and one-way analysis of variance (followed by Student Newman-Keuls multiple range tests) were used to compare paraoxonase activity between centres and between PON55 genotypes in the cases and controls separately. Comparisons between cases and controls for continuous variables were made using ANOVA, adjusting for case-control triplets by the inclusion of terms representing triplets in the model; comparisons were summarised as a difference in means with a $95 \%$ confidence interval, or for variables requiring $\log$ transformation as a ratio of geometric means with a $95 \%$ confidence interval.

To assess the relationship between paraoxonase activity and CHD risk, the subjects were divided into fifths by quintiles of the distribution of paraoxonase activity in the control group. Conditional logistic regression was performed to estimate the odds of CHD risk for each fifth of the paraoxonase distribution relative to the lowest fifth. Tests for heterogeneity in CHD risk between the five categories are presented. Tests for trend in CHD risk across the five categories were obtained by fitting linear terms in the conditional logistic model. Tests were also performed to check for non-linearity in the relationship between risk and the fifths of paraoxonase activity. Two further conditional logistic models were then fitted. In the first model, the odds ratios for paraoxonase activity were adjusted for classical risk factors, namely WHR, diastolic blood pressure (DBP), smoking, total cholesterol, HDL and triglycerides. In the second model, the odds ratios were adjusted for the classical risk factors but also risk factors linked with paraoxonase activity: namely alcohol and apoA-1. Statistical significance was assessed using Wald's test or by comparing the fits of the nested models using likelihood-ratio tests. Likelihood ratio tests were also used to check for evidence of interaction between paraoxonase activity and classical risk factors (WHR, DBP, total cholesterol, triglycerides and smoking category) on CHD risk.

In the genetic analyses, the chi-squared goodness-of-fit test was used to examine, in cases and controls separately, whether or not a genotype distribution was in Hardy-Weinberg equilibrium. Conditional logistic models were used to investigate the relationship between genotype and CHD risk. Results were summarised as odds ratios with $95 \%$ confidence intervals. 
Table 1

Comparison of baseline risk factors between cases and controls

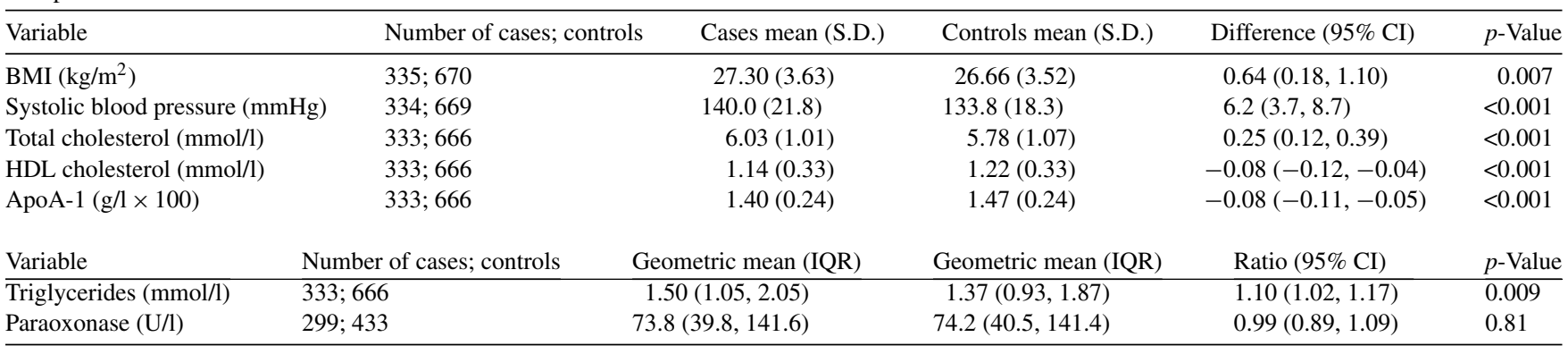

S.D., standard deviation; CI, confidence interval; IQR, interquartile range. Differences in means, ratios of geometric means and $P$-values adjusted for the case-control triplet by using analysis of variance with terms for triplet in the model.

Statistical significance was assessed using the 5\% significance level. Analyses were performed using SPSS 11.0 software (SPSS Inc., Chicago, IL, USA) and STATA 8.0 statistical software (Statacorp, College Station, TX, USA).

\section{Results}

Paraoxonase was significantly positively correlated in both cases and controls with HDL ( $r=0.14$ and 0.11 , respectively) and apoA-1 ( $r=0.17$ and 0.12 , respectively), and in cases only with BMI $(r=0.16)$ and glutathione peroxidase $(r=0.12)$.

Table 1 shows the comparisons of baseline risk factors between cases and controls, adjusted for the triplet grouping. Cases had significantly higher BMI, SBP, total cholesterol and triglycerides, and lower HDL cholesterol and apoA-1 compared with controls. There was no significant difference in paraoxonase activity between cases and controls $(p=0.81)$.

\subsection{Differences between countries}

There was no significant difference in paraoxonase activity between France and Northern Ireland in either cases (geometric mean U/l (IQ range U/l); France, 76.7 (41.1, 149.8); Northern Ireland, 70.0 (39.2, 136.0); $p=0.29)$ or controls (France, 75.7 (40.3, 145.5); Northern Ireland, 72.3 $(40.6,137.3) ; p=0.45)$. HDL concentration was significantly lower in Northern Ireland compared with France in both cases (mean mmol/l (S.D. mmol/l), Northern Ireland, 1.08 (0.10); France, $1.18(0.14) ; p=0.005)$ and controls (Northern Ireland, 1.15 (0.11); France, 1.27 (0.14); $p<0.001)$. ApoA-1 was significantly higher in France compared with Northern Ireland in both cases $($ mean $(\mathrm{g} / \mathrm{l}) \times 100($ S.D. $(\mathrm{g} / \mathrm{l}) \times 100)$, France, $1.42(0.26)$; Belfast, $1.36(0.20) ; p=0.019)$ and controls (France, 1.50 (0.26); Belfast, 1.43 (0.21); $p=0.001)$.

\subsection{Paraoxonase activity and CHD risk}

There was no significant difference in CHD risk between fifths of paraoxonase activity, based on control values, when determined using either a test of heterogeneity between the five categories $(p=0.55)$ or a test for linear trend $(p=0.74)$. Adjustment for classical cardiovascular risk factors and paraoxonase-related factors did not significantly alter this relationship (see Table 2).

\subsection{Interaction with $C H D$ risk factors}

There was no significant interaction between paraoxonase activity and the classical CHD risk factors, namely WHR, DBP, total cholesterol, triglycerides and smoking (data not shown).

Table 2

Conditional logistic regression analysis showing the unadjusted and adjusted odds ratio of CHD risk for fifths of PON1 activity based on control values

\begin{tabular}{llllll}
\hline PON1 (U/l) & $\begin{array}{l}\text { Unadjusted OR }(95 \% \\
\text { CI }(n=293 ; 538)\end{array}$ & $p$-Value & $\begin{array}{l}\text { Adjusted model 1 OR } \\
(95 \% \mathrm{CI})(n=291 ; 531)\end{array}$ & $p$-Value & $\begin{array}{l}\text { Adjusted model 2 OR } \\
(95 \% \text { CI })(n=291 ; 531)\end{array}$ \\
\hline$\leq 38.0$ & 1.00 & & 1.00 & & 1.00 \\
$38.1-51.0$ & $0.93(0.59,1.46)$ & 0.74 & $0.96(0.59,1.57)$ & 0.87 & $0.97(0.59,1.61)$ \\
$51.1-99.5$ & $0.68(0.42,1.09)$ & 0.11 & $0.70(0.42,1.16)$ & 0.17 & $0.72(0.42,1.21)$ \\
$99.6-154.0$ & $0.92(0.59,1.43)$ & 0.70 & $0.94(0.58,1.51)$ & 0.79 & $0.90(0.55,1.47)$ \\
$>154.0$ & $0.92(0.58,1.45)$ & 0.71 & $1.13(0.68,1.88)$ & 0.65 & $1.10(0.65,1.86)$ \\
\hline
\end{tabular}

Unadjusted model: test for heterogeneity: $\chi^{2}=3.04$, d.f. $=4, p=0.55$. Test for trend $\chi^{2}=0.11$, d.f. $=1, p=0.74$; OR 0.98 (95\% CI 0.89, 1.09). Model 1: adjusted for case-control triplet, WHR, DBP, smoking, total cholesterol, HDL cholesterol and triglycerides. Test for heterogeneity: $\chi^{2}=3.59$, d.f. $=4, p=0.46$, test for trend $\chi^{2}=0.13$, d.f. $=1, p=0.72$; OR 1.02 (95\% CI 0.91, 1.14). Model 2: adjusted for model 1 variables (case-control triplet, WHR, DBP, smoking, total cholesterol, HDL cholesterol, triglycerides) and apoA-1, alcohol. Test for heterogeneity: $\chi^{2}=2.88$, d.f. $=4, p=0.58$, test for trend $\chi^{2}=0.04$, d.f. $=1, p=0.84$; OR $1.01(95 \%$ CI $0.90,1.13)$. 
Table 3

Paraoxonase activity according to genotype in cases and controls

\begin{tabular}{llll}
\hline & LL & LM & MM \\
\hline Cases & & & \\
$\quad$ Number (\%) & $111(44.9)$ & $107(43.3)$ & $29(11.7)$ \\
Geometric mean (U/l) & 107.4 & 61.0 & 29.3 \\
IQ range (U/l) & $52.6,172.7$ & $39.2,107.4$ & $26.9,34.3$ \\
Controls & & & \\
$\quad$ Number (\%) & $184(42.5)$ & $191(44.1)$ & $58(13.4)$ \\
Geometric mean (U/l) & 110.2 & 68.4 & 35.9 \\
IQ range (U/l) & $56.1,185.1$ & $41.9,120.5$ & $28.9,40.3$ \\
\hline
\end{tabular}

Comparison of genotype distributions in cases and controls $\left(\chi^{2}=0.62\right.$, d.f. $=2 ; p=0.73$ ). Comparison of paraoxonase levels by genotype in cases $(P<0.001)$. Comparison of paraoxonase levels by genotype in controls $(P<0.001)$

\subsection{PON55 genotype}

The PON55 genotype was in Hardy-Weinberg equilibrium for both cases $(p=0.68)$ and controls $(p=0.45)$ (frequencies shown in Table 3).

There was no significant difference in genotype frequencies between France and Northern Ireland in either cases $(p=0.29)$ or controls $(p=0.82)$ (data not shown).

\subsection{HDL, apoA-1 and paraoxonase activity by genotype}

There was a significant decrease in paraoxonase activity in both cases and controls as the number of M-alleles increased (Table 3). Post hoc multiple range testing demonstrated that the difference between all three genotypes was significant, in both cases and controls. There was no difference in HDL concentration between the genotypes in cases (mean mmol/l (S.D. mmol/l); LL, 1.13 (0.11); LM, 1.09 (0.11); MM, 1.16 $(0.14) ; p=0.33)$ or controls (LL, 1.22 (0.13); LM, $1.20(0.11)$; MM, $1.15(0.11) ; p=0.35)$. Likewise, there was no difference in apoA-1 concentration (mean (S.D.); cases; LL, 1.39 (0.23); LM, 1.38 (0.19); MM, $1.38(0.24) ; p=0.98$; controls; LL, 1.50 (0.24); LM, 1.45 (0.21); MM, 1.45 (0.25); $p=0.12$ ).

\subsection{PON55 genotype and CHD risk}

There was no significant association between genotype and CHD risk ( $\chi^{2}=0.62$, d.f. $\left.=2, p=0.73\right)$; relative to the LL genotype, odds ratios for CHD were not significantly different for the LM genotype (OR 0.92 (95\% CI 0.66, 1.29), $p=0.64$ ) or the MM genotype (OR 0.83 (95\% CI $0.50,1.36$ ), $p=0.45$ ).

\section{Discussion}

As anticipated, paraoxonase activity was correlated with the concentration of its carrier molecule, HDL, and apoA-1. The correlation is weaker than expected; however, paraoxonase is bound to an HDL subfraction, which may be regulated independently of other subfractions. Data on HDL subfractions were not available in PRIME.

\subsection{Paraoxonase activity in France and Northern Ireland}

There was no difference in paraoxonase activity between France and Northern Ireland, despite French cases and controls having higher HDL and apoA-1 concentrations [20], again suggesting that paraoxonase activity is, to some extent, independent of HDL concentration. It is possible that subjects from Northern Ireland have lower paraoxonase concentration, as lower HDL concentration could result in lower enzyme mass, but higher specific enzyme activity, i.e. higher activity per unit enzyme, in agreement with the MONICA study [14].

However, the MONICA study [14] demonstrated that paraoxonase activity was significantly higher in Belfast compared with Toulouse, a finding at odds with those of the PRIME study. One explanation for this difference is that the populations are not directly comparable; approximately $50 \%$ of the MONICA populations were female. While there is not thought to be a sex-difference in paraoxonase activity [21] it is possible that this may have some bearing on either HDL concentration or paraoxonase enzyme concentration, and thus also paraoxonase activity. Also, as it is not possible to compare demographic data from the MONICA study [14] with that in PRIME, it is impossible to comment on whether there were significant differences between these studies with regard to variables that are likely to alter paraoxonase activity, e.g. diet.

\subsection{Paraoxonase activity in cases and controls}

No significant difference in paraoxonase activity was found between cases and controls, despite significantly lower HDL and apoA-1 concentrations in cases, again suggesting that paraoxonase activity is independent of HDL concentration. It could also indicate a lower paraoxonase enzyme mass, which raises the question as to whether there is a difference in paraoxonase specific activity between cases and controls. Serum paraoxonase activity and concentration were significantly lower, but specific activity significantly higher in patients post-MI compared with controls [22]. At 6 weeks post-MI, there was no significant variation in either paraoxonase specific activity or concentration. In a second study, paraoxonase activity, concentration and specific activity were significantly lower in subjects with angiographically proven CHD compared with controls [23].

It is certainly a weakness of PRIME that enzyme concentration was not measured as this could establish whether there is an association between specific enzyme activity and CHD risk. Interestingly, the only other prospective study investigating the association between paraoxonase activity and CHD risk also failed to include data on enzyme concentration [13]. 
In the PRIME study, there was no association between paraoxonase activity and CHD risk, which disagrees with the only other prospective study on paraoxonase activity and CHD risk to date [13].

In the Caerphilly Prospective Study [13] paraoxonase activity was lower in the 163 men who had a coronary event during the 15 years of follow-up. It is of note that in this study paraoxonase activity was a stronger prognostic factor in subjects with pre-existing CHD or who were in the highest tertile of CHD risk as predicted by the Framingham equation [24], which is consistent with the suggestions by previous studies that paraoxonase may require the presence of other factors predisposing to CHD for it to emerge as a risk factor [25]. This may partially account for the negative result seen in PRIME.

However, although the Caerphilly study had a longer follow-up period (15 years) compared with PRIME (5 years), it was a cohort study investigating a substantially smaller number of subjects ( $n=1353)$, than the PRIME study $(n=9758)$. In the Caerphilly study, comparisons were made directly between the 163 subjects who experienced a new cardiac event and the remaining 1190 subjects, whereas in the PRIME study, the 335 subjects who experienced an event were each matched with two CHD-free controls. In Caerphilly, quintiles were based on the entire cohort paraoxonase activity whereas in PRIME, they were based on control paraoxonase activity. Finally in the Caerphilly study the evidence that paraoxonase activity is a stronger risk factor in the presence of CHD is based on paraoxonase activity quintiles from 313 subjects. Therefore, although a positive association between paraoxonase activity and CHD risk was demonstrated in the Caerphilly study, this may be accounted for by the study design, cohort size and statistical methods applied to the analysis.

A second earlier study investigating the association between paraoxonase activity and carotid artery disease [26] found that paraoxonase activity was significantly lower in cases compared with controls and in multiple logistic regression was a significant predictor of carotid artery disease. Again this disagrees with the negative findings of the PRIME study. However, this was a case-control study involving smaller numbers (106 cases and 106 controls) and used an endpoint that is not directly comparable with CHD events.

Cross-sectional [27] and case-control studies [28,29] have not consistently shown an association between paraoxonase activity and various end-points of CHD, although two case-control studies yielded a positive association [26,30]. However, the smaller numbers of subjects involved in these studies may account for the contradictory results.

\subsection{PON55 genotype}

The relationship between genotype and CHD risk is becoming ever more complicated with the emerging importance of promoter polymorphisms, some of which are in linkage disequilibrium with the coding polymorphisms and alter enzyme activity and concentration $[31,32]$. Thus, the benefit of investigating the relationship between the coding polymorphisms and CHD risk without considering confounding by promoter polymorphisms is limited.

\subsection{Activity, HDL and apoA-1 according to PON55 genotype}

As expected, enzyme activity decreased as the number of L-alleles decreased, given that the L-allele is associated with high enzyme activity toward paraoxon [8].

There was no difference in HDL and apoA-1 concentration between genotypes, indicating no influence of PON55 on HDL concentration.

We have only measured the PON55 genotype in the current study. So far there have been five polymorphisms identified in the $5^{\prime}$ regulatory of the paraoxonase gene: C107T [33], G126C, G160A [34], A824G, C907G [33], and an additional polymorphism identified in the coding region (G160R) [35].

It has been calculated that the 108 polymorphism accounts for $22.8 \%$ of the variation in paraoxonase activity; the 192 site for $5.7 \%$; the 55 site for $4.1 \%$ and the 162 polymorphism for $1.1 \%$ with the effect of the 909 polymorphism being marginal [32]. There may be linkage [32,34] or at least a complex interaction [36] between the 192 site and the 107 promoter polymorphism, which could confound the association between the R192 allele and paraoxonase activity in earlier studies.

The increasing genetic complexity of the association between polymorphisms, promoter polymorphisms and paraoxonase activity will make it difficult for future studies to elucidate the contribution of each single nucleotide polymorphism to paraoxonase activity and CHD risk.

\subsection{PON55 polymorphism and disease risk}

The LL genotype is less protective of LDL oxidation than the MM genotype [12], therefore an association between CHD risk and the LL genotype would be expected, and indeed an association has been demonstrated between PON55 LL and arterial atherosclerosis [37-39].

In the PRIME case-control cohort there was no association between the PON55 polymorphism and CHD risk, in agreement with a recent meta-analysis involving 11,212 CHD cases and 12,786 controls [40].

While it is possible that the PON55 is in linkage disequilibrium with an unknown functional variant, with the degree of linkage varying between populations or differing gene frequencies between populations altering the association with disease risk [41], the negative results of meta-analysis [40] make these possibilities increasingly unlikely. 


\subsection{PRIME study strengths and limitations}

The strengths of the PRIME study lie in its nested, case-control study design. This maximises the power of the study per unit cost, minimises the bias to which a case-control study is susceptible, while maintaining the advantages associated with an observational cohort study. The choice of controls was superior to that of a case-control study, as they were selected from the risk-set, and matched to cases on age, date of examination and recruitment centre.

However, there are a number of potential limitations.

PRIME was at risk of regression dilution bias as only one measurement of each variable was performed per subject at baseline. Subjects with pre-existing CHD were excluded at baseline from follow-up, which may contribute to the negative association between paraoxonase activity and CHD risk. The study investigated males only. In order to generate an adequate number of CHD cases, middle-aged men were studied; it is possible that a longer prospective study in younger patients may yield different results. Finally, paraoxonase enzyme concentration was not measured; this additional data could establish whether there is an association between specific enzyme activity and CHD risk.

\section{Conclusions}

These results suggest that there is no association between paraoxonase activity, or the PON55 polymorphism, and CHD risk in healthy middle-aged men in the PRIME study. This is only the second prospective study to investigate the association between paraoxonase activity and CHD risk, and contradicts the findings of the previous prospective study [13].

Thus, the results of the PRIME study do not support the hypothesis that the paraoxonase enzyme is a novel cardiovascular risk factor, in regard to either its activity or genotype.

Further investigation into the effect of activity and concentration are needed before a conclusion can be drawn regarding the relationship between paraoxonase and CHD.

\section{Acknowledgements}

We thank the following organizations which allowed the recruitment of the PRIME subjects: the Health screening centres organized by the Social Security of Lille (Institut Pasteur), Strasbourg, Toulouse and Tourcoing; Occupational Medicine Services of Haute-Garonne, of the Urban Community of Strasbourg; the Association Inter-entreprises des Services Médicaux du Travail de Lille et environs; the Comité pour le Développement de la Médecine du Travail; the Mutuelle Générale des PTT du Bas-Rhin; the Laboratoire d'Analyses de l'Institut de Chimie Biologique de la Faculté de Médecine de Strasbourg; the Department of Health (NI) and the Northern Ireland Chest Heart and Stroke Association.

\section{Appendix A. The PRIME Study Group}

The PRIME Study is organized under an agreement between INSERM and the Merck, Sharpe and Dohme-Chibret Laboratory, with the following participating Laboratories:

Strasbourg MONICA Project, Department of Epidemiology and Public Health, Faculty of Medicine, Strasbourg, France (D. Arveiler, B. Haas).

Toulouse MONICA Project, INSERM U558, Department of Epidemiology, Paul Sabatier-Toulouse Purpan University, Toulouse, France (J. Ferrières, J.B. Ruidavets).

Lille MONICA Project, INSERM U508, Pasteur Institute, Lille, France (P. Amouyel, M. Montaye).

Department of Epidemiology and Public Health, Queen's University, Belfast, Northern Ireland (A. Evans, J. Yarnell, F. Kee).

Department of Atherosclerosis, INSERM UR545, Lille, France (G. Luc, J.M. Bard).

Laboratory of Haematology, La Timone Hospital, Marseilles, France (I. Juhan-Vague).

Laboratory of Endocrinology, INSERM U326, Toulouse, France (B. Perret).

Vitamin Research Unit, The University of Bern, Bern, Switzerland (F. Gey).

Nutrition and Metabolism Group, Centre for Clinical and Population Science, Queen's University Belfast, Northern Ireland (Jayne Woodside, Ian Young).

DNA Bank, INSERM U525, Paris, France (F. Cambien).

Coordinating Center, INSERM U258, Paris-Villejuif, France (P. Ducimetière, A. Bingham).

\section{References}

[1] Ross R. The pathogenesis of atherosclerosis: a perspective for the 1990s. Nature 1993;362:801-9.

[2] Heller RF, Chinn S, Pedoe HD, Rose G. How well can we predict coronary heart disease? Findings in the United Kingdom Heart Disease Prevention Project. Br Med J (Clin Res Ed) 1984;288:1409-11.

[3] Yarnell JW. The PRIME study: classical risk factors do not explain the several fold differences in risk of coronary heart disease between France and Northern Ireland. Prospective Epidemiological Study of Myocardial Infarction. QJM 1998;91:667-76.

[4] Scarabin PY, Arveiler D, Amouyel P, et al. Plasma fibrinogen explains much of the difference in risk of coronary heart disease between France and Northern Ireland. The PRIME study. Atherosclerosis 2003;166:103-9.

[5] Blatter MC, James RW, Messmer S, Barja F, Pometta D. Identification of a distinct human high-density lipoprotein subspecies defined by a lipoprotein-associated protein, K-45. Identity of K-45 with paraoxonase. Eur J Biochem 1993;211:871-9.

[6] Adkins S, Gan KN, Mody M, La Du BN. Molecular basis for the polymorphic forms of human serum paraoxonase/arylesterase: glutamine or arginine at position 191, for the respective A or B allozymes. Am J Hum Genet 1993;52:598-608.

[7] Humbert R, Adler DA, Disteche CM, et al. The molecular basis of the human serum paraoxonase activity polymorphism. Nat Genet 1993;3:73-6. 
[8] Mackness B, Mackness MI, Arrol S, Turkie W, Durrington PN. Effect of the molecular polymorphisms of human paraoxonase (PON1) on the rate of hydrolysis of paraoxon. Br J Pharmacol 1997;122:265-8.

[9] Mackness MI, Arrol S, Abbott C, Durrington PN. Protection of lowdensity lipoprotein against oxidative modification by high-density lipoprotein associated paraoxonase. Atherosclerosis 1993;104:129-35.

[10] Aviram M, Rosenblat M, Bisgaier CL, et al. Paraoxonase inhibits highdensity lipoprotein oxidation and preserves its functions. A possible peroxidative role for paraoxonase. J Clin Invest 1998;101:1581-90.

[11] Aviram M, Rosenblat M, Billecke S, et al. Human serum paraoxonase (PON 1) is inactivated by oxidized low density lipoprotein and preserved by antioxidants. Free Radic Biol Med 1999;26:892-904.

[12] Mackness B, Mackness MI, Arrol S, Turkie W, Durrington PN. Effect of the human serum paraoxonase 55 and 192 genetic polymorphisms on the protection by high density lipoprotein against low density lipoprotein oxidative modification. FEBS Lett 1998;423:57-60.

[13] Mackness B, Durrington P, McElduff P, et al. Low paraoxonase activity predicts coronary events in the Caerphilly Prospective Study. Circulation 2003;107:2775-9.

[14] Mackness B, Mackness MI, Durrington PN, et al. Paraoxonase activity in two healthy populations with differing rates of coronary heart disease. Eur J Clin Invest 2000;30:4-10.

[15] Tunstall-Pedoe H, Kuulasmaa K, Amouyel P, et al. Myocardial infarction and coronary deaths in the World Health Organization MONICA Project. Registration procedures, event rates, and case-fatality rates in 38 populations from 21 countries in 4 continents. Circulation 1994;90:583-612.

[16] Ducimetiere P, Ruidavets JB, Montaye M, Haas B, Yarnell J. Fiveyear incidence of angina pectoris and other forms of coronary heart disease in healthy men aged 50-59 in France and Northern Ireland: the Prospective Epidemiological Study of Myocardial Infarction (PRIME) Study. Int J Epidemiol 2001;30:1057-62.

[17] Rose GA, Blackburn H, Gillum RR, Prineas RJ. Cardiovascular survey methods. 2nd ed. Geneva: World Health Organisation; 1982.

[18] Ortigoza-Ferado J, Richter RJ, Hornung SK, Motulsky AG, Furlong CE. Paraoxon hydrolysis in human serum mediated by a genetically variable arylesterase and albumin. Am J Hum Genet 1984;36: 295-305.

[19] Gan KN, Smolen A, Eckerson HW, Ladu BN. Purification of human serum paraoxonase arylesterase-evidence for one esterase catalyzing both activities. Drug Metab Dispos 1991;19:100-6.

[20] Luc G, Bard JM, Ferrieres J, et al. Value of HDL cholesterol, apolipoprotein A-I, lipoprotein A-I, and lipoprotein A-I/A-II in prediction of coronary heart disease: the PRIME Study. Prospective Epidemiological Study of Myocardial Infarction. Arterioscler Thromb Vasc Biol 2002;22:1155-61.

[21] Mackness B, Durrington P, Mackness M. Human serum paraoxonase. Gen Pharmacol 1998;31(3):329-36.

[22] Ayub A, Mackness MI, Arrol S, et al. Serum paraoxonase after myocardial infarction. Arterioscler Thromb Vasc Biol 1999;19:330-5.

[23] Mackness B, Davies GK, Turkie W, et al. Paraoxonase status in coronary heart disease: are activity and concentration more important than genotype? Arterioscler Thromb Vasc Biol 2001;21:1451-7.

[24] Wilson PW, D'Agostino RB, Levy D, et al. Prediction of coronary heart disease using risk factor categories. Circulation 1998;97:1837-47.
[25] Ruiz J, Blanche H, James RW, et al. Gln-Arg192 polymorphism of paraoxonase and coronary heart disease in type 2 diabetes. Lancet 1995;346:869-72.

[26] Jarvik GP, Rozek LS, Brophy VH, et al. Paraoxonase (PON1) phenotype is a better predictor of vascular disease than is PON1(192) or PON1(55) genotype. Arterioscler Thromb Vasc Biol 2000;20:2441-7.

[27] Horter MJ, Sondermann S, Reinecke H, et al. Associations of HDL phospholipids and paraoxonase activity with coronary heart disease in postmenopausal women. Acta Physiol Scand 2002;176:123-30.

[28] Karakaya A, Ibis S, Kural T, Kose SK, Karakaya AE. Serum paraoxonase activity and phenotype distribution in Turkish subjects with coronary heart disease and its relationship to serum lipids and lipoproteins. Chem Biol Interact 1999;118:193-200.

[29] Rahmani M, Raiszadeh F, Allahverdian S, et al. Coronary artery disease is associated with the ratio of apolipoprotein $\mathrm{A}-\mathrm{I} / \mathrm{B}$ and serum concentration of apolipoprotein $\mathrm{B}$, but not with paraoxonase enzyme activity in Iranian subjects. Atherosclerosis 2002;162:381-9.

[30] Jarvik GP, Hatsukami TS, Carlson C, et al. Paraoxonase activity, but not haplotype utilizing the linkage disequilibrium structure, predicts vascular disease. Arterioscler Thromb Vasc Biol 2003;23:1465-71.

[31] Brophy VH, Hastings MD, Clendenning JB, et al. Polymorphisms in the human paraoxonase (PON1) promoter. Pharmacogenetics 2001;11:77-84.

[32] Brophy VH, Jampsa RL, Clendenning JB, et al. Effects of 5' regulatoryregion polymorphisms on paraoxonase-gene (PON1) expression. Am J Hum Genet 2001;68:1428-36.

[33] Leviev I, James RW. Promoter polymorphisms of human paraoxonase PON1 gene and serum paraoxonase activities and concentrations. Arterioscler Thromb Vasc Biol 2000;20:516-21.

[34] Suehiro T, Nakamura T, Inoue M, et al. A polymorphism upstream from the human paraoxonase (PON1) gene and its association with PON1 expression. Atherosclerosis 2000;150:295-8.

[35] Wang X, Fan Z, Huang J, et al. Extensive association analysis between polymorphisms of PON gene cluster with coronary heart disease in Chinese Han population. Arterioscler Thromb Vasc Biol 2003;23:328-34.

[36] James RW, Leviev I, Ruiz J, et al. Promoter polymorphism T(-107)C of the paraoxonase PON1 gene is a risk factor for coronary heart disease in type 2 diabetic patients. Diabetes 2000;49:1390-3.

[37] Schmidt H, Schmidt R, Niederkorn K, et al. Paraoxonase PON1 polymorphism leu-Met54 is associated with carotid atherosclerosis: results of the Austrian Stroke Prevention Study. Stroke 1998;29:2043-8.

[38] Malin R, Jarvinen O, Sisto T, Koivula T, Lehtimaki T. Paraoxonase producing PON1 gene M/L55 polymorphism is related to autopsy-verified artery-wall atherosclerosis. Atherosclerosis 2001;157:301-7.

[39] Fortunato G, Rubba P, Panico S, et al. A paraoxonase gene polymorphism, PON 1 (55), as an independent risk factor for increased carotid intima-media thickness in middle-aged women. Atherosclerosis 2003;167:141-8.

[40] Wheeler JG, Keavney BD, Watkins H, Collins R, Danesh J. Four paraoxonase gene polymorphisms in 11,212 cases of coronary heart disease and 12,786 controls: meta-analysis of 43 studies. Lancet 2004;363:689-95.

[41] Sanghera DK, Saha N, Kamboh MI. The codon 55 polymorphism in the paraoxonase 1 gene is not associated with the risk of coronary heart disease in Asian Indians and Chinese. Atherosclerosis 1998;136:217-23. 